\title{
Long-term results of aortic valve-sparing operations in patients with Marfan syndrome
}

\author{
Tirone E. David, MD, Sue Armstrong, BSc, Manjula Maganti, BSc, Jack Colman, MD, and
}

Timothy J. Bradley, MBChB

Objective: The appropriateness of aortic valve-sparing operations in patients with Marfan syndrome has been
questioned. This study examines the long-term results of these operations in patients with Marfan syndrome.

Methods: From 1988 to 2006, 103 consecutive patients with Marfan syndrome (mean age, $37 \pm 12$ years) and aortic root aneurysm had aortic valve-sparing operations. Emergency surgery was performed in 11 patients: 8 for acute type A aortic dissection and 3 for unexplained persistent chest pain. Fourteen patients also had mitral valve surgery. The technique of aortic valve reimplantation was used in 77 patients, and aortic root remodeling was used in 26 patients. Patients were followed prospectively and underwent annual echocardiographic studies. The mean follow-up was $7.3 \pm 4.2$ years and $100 \%$ complete.

Results: There was 1 operative death and 5 late deaths. Four of the 6 deaths were due to complications of aortic dissections. The patients' survival at 15 years was $87.2 \%$ compared with $95.6 \%$ for the general population of Ontario matched for age and sex. Seven patients had important aortic insufficiency: 4 mild to moderate, 2 moderate, and 1 moderate to severe. Freedom from greater than mild aortic insufficiency at 15 years was $79.2 \%$. Three patients, all after aortic root remodeling, had aortic valve replacement, 2 for aortic insufficiency and 1 for endocarditis. At the most recent follow-up, 97 patients were alive: 86 were in functional class I, and 11 were in functional class II.

Conclusions: Aortic valve-sparing operations provided excellent clinical outcomes in this series of patients with Marfan syndrome. Postoperatively, complications of aortic dissections were the leading cause of death.

Earn CME credits at

http://cme.ctsnetjournals.org

Aortic root aneurysm is a cardinal manifestation of Marfan syndrome and the most important determinant of prognosis. Without surgical intervention, many patients die in the third decade of their lives from complications of aortic root aneurysm, such as aortic rupture, aortic dissection, and aortic insufficiency $(\mathrm{AI}){ }^{1,2}$ Aortic root replacement dramatically improves the survival of these patients. ${ }^{3}$ However, because of their young age at the time when surgical intervention is recommended, mechanical aortic valves are often used, exposing them to a constant risk of hemorrhage, thromboembolism, and prosthetic valve endocarditis. ${ }^{3}$ Aortic valve-sparing operations are an alternative to aortic root replacement to treat aortic root aneurysm, and because the na-

From the Peter Munk Cardiac Centre of Toronto General Hospital, University Health Network and University of Toronto, Toronto, Ontario, Canada.

Read at the Eighty-ninth Annual Meeting of the American Association for Thoracic

Surgery, Boston, Mass, May 9-13, 2009.

Received for publication Feb 11, 2009; revisions received April 12, 2009; accepted for publication June 15, 2009; available ahead of print Aug 3, 2009.

Address for reprints: Tirone E. David, MD, 200 Elizabeth St-4N457, Toronto, Ontario

M5G 2C4, Canada (E-mail: tirone.david@uhn.on.ca).

J Thorac Cardiovasc Surg 2009;138:859-64

$0022-5223 / \$ 36.00$

Copyright $₫ 2009$ by The American Association for Thoracic Surgery

doi:10.1016/j.jtcvs.2009.06.014 tive aortic valve cusps are preserved, no anticoagulation is required. ${ }^{4,5}$ Although aortic valve-sparing operations have been performed during the past 2 decades in a few centers, ${ }^{4,5}$ only recently have these procedures been widely adopted as an alternative to aortic root replacement with mechanical or biologic valved conduits in patients with Marfan syndrome. ${ }^{6,7}$ This study examines the long-term results of aortic valve-sparing operations in patients with Marfan syndrome by a single surgeon at a single institution.

\section{MATERIALS AND METHODS}

Aortic valve-sparing operations were performed in 103 consecutive patients with Marfan syndrome at the Peter Munk Cardiac Centre at Toronto General Hospital from July 1988 to December 2006. The diagnosis of Marfan syndrome was made according to the Ghent criteria. ${ }^{8}$ The patients' mean age at the time of the operation was $37 \pm 12$ years (range, 12-65 years), and $74(72 \%)$ were men. The operation was elective in 92 patients and urgent/emergency in 11 patients. The reason for an urgent/ emergency operation was acute type A aortic dissection in 8 patients (2 in cardiogenic shock) and unexplained chest pain in 3 patients. In the remaining 92 patients, the main indication for surgical intervention was an aortic root aneurysm of $50 \mathrm{~mm}$ or larger in diameter in 83 patients and severe AI, mitral insufficiency, or both associated with an aortic root diameter of less than $50 \mathrm{~mm}$ in 9 patients. Overall, the mean diameter of the aortic sinuses was $53.3 \pm 4.8 \mathrm{~mm}$ (range, $41-70 \mathrm{~mm}$ ). Three patients had previous replacement of the ascending aorta for acute type A aortic dissection. Overall, 11 patients had type A aortic dissection, 8 had acute dissection, and 3 had chronic dissection. Preoperative echocardiographic analysis disclosed that the aortic valve was tricuspid in 100 patients and bicuspid in 3 patients. Only 15 patients had moderate or severe AI, and 14 patients had moderate or severe mitral insufficiency (1 with a heavily calcified mitral annulus). Three patients (ages 42, 50, and 60 years) had coronary artery disease. In addition, 2 patients were diabetic, 1 patient had chronic renal failure 


\section{Abbreviation and Acronym \\ $\mathrm{AI}=$ aortic insufficiency}

on hemodialysis, and 2 patients had severe chronic obstructive pulmonary disease (forced expiratory volume in 1 second, $<1.0 \mathrm{~L} / \mathrm{s}$ ). Eleven patients had severe pectus excavatum, and 2 patients had previous repair of this deformity. The Review Ethics Board of the University Health Network approved this study.

\section{Operative Procedures}

Two types of aortic valve-sparing operations, reimplantation of the aortic valve and remodeling of the aortic root, were performed without a criterion for performance of one or the other during the first decade of the study, but during the second decade, only reimplantation of the aortic valve was used because it was believed to be more durable in patients with Marfan syndrome. ${ }^{9}$ Remodeling of the aortic root was used in 26 patients, and reimplantation of the aortic valve was used in 77 patients. The size of the graft used for remodeling of the aortic root was $27 \pm 2.4 \mathrm{~mm}$ (range, 24$30 \mathrm{~mm}$ ), and for reimplantation of the aortic valve, graft size was $30 \pm$ $3.1 \mathrm{~mm}$ (range, 26-34 mm). Among patients who had reimplantation of the aortic valve, 35 had a straight Dacron tube, and the more recent 42 had neoaortic sinuses created by plicating the tubular graft between commissures. Prolapse of 1 or more aortic cusps after reconstruction of the aortic root was present in 30 patients and was corrected by shortening the free margin of the cusp by means of plication in the area of the nodule of Arantius or by shortening and reinforcement of the free margin by weaving a double layer of 6-0 Gore-Tex sutures (W. L. Gore \& Associates, Inc, Tempe, Ariz) from commissure to commissure. Only 1 patient required a second pump run to correct mild-to-moderate AI caused by unrecognized cusp prolapse.

In addition to the aortic valve-sparing operation, the mitral valve was repaired in 13 patients and replaced with a bioprosthetic valve in 1 patient who also had reconstruction of the mitral annulus because of heavy calcification. Four patients had coronary artery bypass, 3 because of coronary artery disease and 1 because of acute aortic dissection with a tear into the origin of the right coronary artery and preoperative signs of inferior wall ischemia. Four patients had replacement of the transverse aortic arch because of acute or chronic aortic dissection. One patient also had concomitant repair of an abdominal aortic aneurysm.

Patients who underwent concomitant mitral valve surgery were anticoagulated with warfarin sodium during the first 3 postoperative months. $\mathrm{Pa}$ tients were discharged on a $\beta$-blocker agent, except for 5 patients who received a calcium antagonist ( 2 patients) or an angiotensin-converting enzyme inhibitor ( 3 patients) because of intolerance to the $\beta$-blocker.

\section{Follow-up}

Patients were followed in our adult congenital heart clinic. Echocardiographic analysis was performed annually. Imaging of the entire thoracic and abdominal aorta was obtained annually in patients with aortic dissection and every 3 to 5 years in the others. AI was graded as none, trivial, mild, moderate, and severe on the basis of information from color flow mapping and continuous-wave Doppler echocardiography. ${ }^{10}$ The median follow-up was 7.18 years (mean, $7.3 \pm 4.2$ years) and was $100 \%$ complete.

\section{Statistical Analysis}

All data analyses were performed with SAS 9.1 software (SAS Institute, Inc, Cary, NC). Categorical variables are reported as frequencies, and all continuous variables are reported as means \pm standard deviations. Statistical comparison between the study groups was tested with the unpaired $t$ test or nonparametric Wilcoxon test for continuous variables and the $\chi^{2}$ test or
Fisher's exact test for categorical variables. The Kaplan-Meier method was used to calculate estimates for long-term survival or freedom from morbid events. Survival estimates for the age- and sex-matched Ontario general population were obtained from the Life Table Template V1.2, a downloadable Excel spreadsheet available at http://www.healthinformation.on.ca. All preoperative variables with a univariate $P$ value of less than .25 or those with known biologic significance but failing to meet this critical $\alpha$ level were submitted to the multivariable model for Cox regression analysis to determine the independent multivariable predictors of late outcomes. Variable retention criteria in the model were set at a $P$ value of .05 .

\section{RESULTS}

One patient died the day after aortic valve reimplantation of a new acute type B aortic dissection with malperfusion. The dissection was not recognized until the patient showed profound acidosis and irreversible shock.

One patient experienced cardiac arrest and rupture of the liver during resuscitation and was successfully treated with surgical repair of the liver. Ten patients required re-exploration of the mediastinum for bleeding. Perioperative blood transfusion was needed in 76 patients. Eleven patients had transient postoperative atrial fibrillation. One patient required a permanent pacemaker after the aortic valve-sparing operation, mitral valve repair, and myocardial revascularization. There were no strokes, new myocardial infarctions, new renal failures, respiratory failures, wound infections, or any other serious postoperative complication.

Five patients died during the follow-up period: 1 of an acute type B aortic dissection during pregnancy, ${ }^{11} 1$ of rupture of the false lumen of a chronic type A dissection, 1 during abdominal aortic surgery for chronic aortic dissection, 1 of chronic obstructive lung disease, and 1 of pneumonia. Cox regression analysis did not identify any independent predictor of death. The patients' survival at 15 years was $87.2 \%$ compared with $95.6 \%$ for the general population of Ontario matched for age and sex (Figure 1).

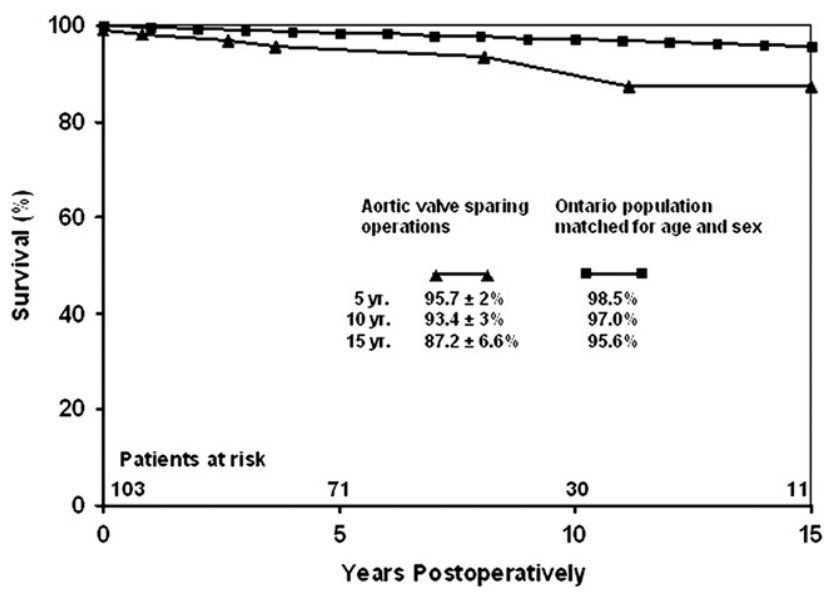

FIGURE 1. Long-term survival of patients with Marfan syndrome after aortic valve-sparing operations compared with the general population of Ontario matched for age and sex. 
Three patients experienced a transient ischemic attack, and computed tomographic scanning did not show any intracranial abnormality. Two of these patients had chronic type A aortic dissections with tears in the aortic arch. One patient with known coronary artery disease had a myocardial infarction.

One patient had severe mitral insufficiency and underwent successful mitral valve repair 8.3 years after the aortic valve-sparing operation. One patient underwent replacement of the entire thoracic and abdominal aorta because of rupture of the false lumen and became paraplegic. This patient had infective endocarditis with an aortic root abscess caused by Enterococcus faecalis 11.8 years postoperatively and was successfully treated with aortic root replacement with an aortic valve homograft. One patient had surgical intervention for a ruptured false lumen of the abdominal aorta and died at the time of the operation.

Two patients had aortic valve replacement for AI (moderate in 1 and moderate to severe in 1) with mechanical valves, and 1 patient had aortic root replacement for infective endocarditis with an aortic valve homograft. All 3 patients survived the reoperation. The original procedure had been remodeling of the aortic root in all 3 patients. Figure 2 shows the freedom from reoperation on the aortic root, which at 5 , 10 , and 15 years was $100 \%, 94.9 \% \pm 3.5 \%$, and $87.6 \% \pm$ $7.7 \%$, respectively.

The latest echocardiographic study before death or reoperation in 102 patients who survived the operation showed no $\mathrm{AI}$ in 33 , trivial $\mathrm{AI}$ in 25 , mild $\mathrm{AI}$ in 27, mild-to-moderate $\mathrm{AI}$ in 4, moderate $\mathrm{AI}$ in 2, and moderate-to-severe $\mathrm{AI}$ in 1. Thus 7 patients had greater than mild AI: 5 had undergone aortic root remodeling, and 2 had undergone aortic valve reimplantation. Only 2 of these 7 patients had had aortic cusp repair, and only 1 had moderate or severe AI preoperatively. Figure 3 shows the Kaplan-Meier estimates of freedom from greater than mild $\mathrm{AI}$ in the entire group, which at 5,10, and

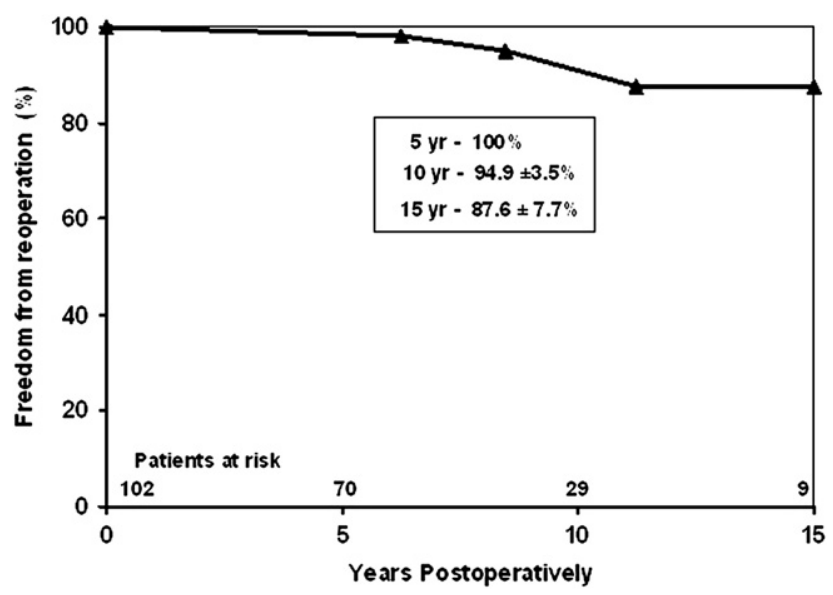

FIGURE 2. Kaplan-Meier estimates on freedom from reoperation on the aortic root after aortic valve-sparing operations.

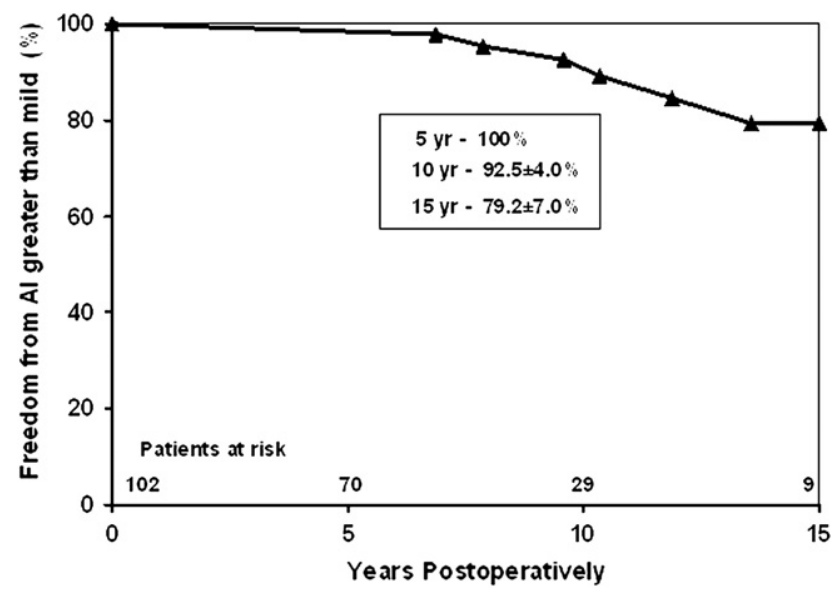

FIGURE 3. Kaplan-Meier estimates on freedom from aortic insufficiency (AI) greater than mild after aortic valve-sparing operations.

15 years were $100 \%, 92.5 \% \pm 4.0 \%$, and $79.2 \% \pm 8.1 \%$, respectively. Freedom from greater than mild AI at 15 years was $66.5 \% \pm 13.2 \%$ after aortic root remodeling and $94.7 \% \pm 5.1 \%$ after aortic valve reimplanation $(P=.12)$. We could not identify any predictor of AI using univariate or multivariate analyses. The mean follow-up of patients who had remodeling was longer than in patients who had reimplantation $(9.7 \pm 2.8$ vs $6.0 \pm 4.5$ years, $P=.001)$.

At the latest follow-up contact, 97 patients were alive (3 had had aortic valve/root replacement): 86 were in New York Heart Association functional class I, and 11 were in class II.

\section{DISCUSSION}

Until a decade ago, many surgeons believed that aortic valve-sparing operations should not be performed in patients with Marfan syndrome because the aortic cusps often revealed fragmented fibrillin on indirect immunofluorescence examination. ${ }^{12,13}$ This abnormality was also seen in patients with myxomatous degeneration of the mitral valve. $^{12,13}$ If repair of the mitral valve is the standard treatment for patients with mitral regurgitation caused by myxomatous degeneration, why should aortic valve-sparing operations not be the same for aortic root aneurysm? The results of this study indicate that in our experience aortic valve-sparing operations are as durable as mitral valve repair for myxomatous disease. ${ }^{14}$

This study examines the clinical and echocardiographic outcomes of 103 consecutive patients with Marfan syndrome and aortic root aneurysm who had aortic valve-sparing operations during the past 2 decades. During the same time interval, 49 patients with Marfan syndrome had aortic root replacement with valved conduits, mostly during the first decade of this study. The criterion based on the diameter of the aortic sinuses to recommend surgical intervention in patients with Marfan syndrome changed during this study. 
Early on, we used $55 \mathrm{~mm}$, but as our experience increased, we reduced to $50 \mathrm{~mm}$, and more valves could be saved. We believe that the diameter of the aortic root is the most important determinant of the feasibility of aortic valve-sparing operations because roots with diameters of greater than 60 $\mathrm{mm}$ often have a grossly dilated sinotubular junction and aortic annulus, which damages the aortic cusps beyond advisability of repair. Our decision to preserve or replace the aortic valve is largely dependent on the quality of the aortic cusps. Thinned and overstretched cusps with stress fenestrations along the commissural areas are not preserved, and aortic root replacement is deemed a better option. Normal or near-normal aortic cusps or in cases in which only 1 cusp is abnormal (prolapse, large stress fenestration, or both) are preserved by means of the aortic valve-sparing operation, and the damaged cusp is repaired. Judicious use of cusp repair has not affected the durability of aortic valvesparing operations in our experience. ${ }^{15}$ Remodeling of the aortic root is technically less demanding than reimplantation of the aortic valve and is functionally superior, ${ }^{16}$ but it is less durable, particularly when the aortic annulus is dilated. ${ }^{9,17}$ Actually, we believe that even if the aortic annulus is normal at the time of surgical intervention, it can dilate after remodeling of the aortic root and cause AI in young patients with Marfan syndrome. ${ }^{9}$ Several studies have shown that aortic valve function is more stable after reimplantation than after remodeling. ${ }^{17-19}$ In the present study 26 patients had remodeling of the aortic root, and 5 had greater than mild AI, all because of late dilation of the aortic annulus. Remodeling is functionally superior to reimplantation because it preserves the function of the aortic annulus and creates neoaortic sinuses. ${ }^{16}$ The aortic annulus becomes rigid after reimplantation and functions like a stent for the aortic valve cusps, but it is possible to create neoaortic sinuses by using a graft 4 to $5 \mathrm{~mm}$ larger than needed for the size of the cusps and plicating the spaces between commissures at the subannular level, as well as at the level of the sinotubular junction. This maneuver has been shown to reduce the velocity of closure of the aortic valve, and it might reduce stress on the cusps. $^{20,21}$ There is now a commercially available graft with neoaortic sinuses, the Valsalva Graft (Sulzer Vascutek, Renfrewshire, Scotland). ${ }^{22}$ There are no data on late outcomes of aortic valve reimplantation with the Valsalva Graft, but a small international series of 35 patients with Marfan syndrome who had this graft showed a freedom from reoperation caused by $\mathrm{AI}$ of $88.9 \%$ at 5 years. ${ }^{7}$

Comparative studies of retrospective series on aortic root replacement with mechanical valves and aortic valve-sparing operations in patients with Marfan syndrome have failed to show superiority of one surgical approach over the other. ${ }^{6,9,23}$ Aortic root replacement with mechanical valves provide excellent freedom from reoperation caused by aortic valve failure but is associated with a constant risk of thromboembolism, anticoagulation-related hemorrhage, and infec- tive endocarditis, ${ }^{3}$ whereas reoperation for $\mathrm{AI}$ is the major problem with aortic valve-sparing operations. ${ }^{7,17-19,23}$ In the series by Gott and colleagues, ${ }^{13}$ of 271 patients who had surgical intervention for aortic root aneurysm, the 15 -year survival was $76 \%$. This series included children, 48 patients with aortic dissections, 15 patients who had aortic homografts placed, and 24 patients who had aortic valve-sparing operations. There were 2 operative and 43 late deaths, but only 10 caused by complications of aortic dissections ( 2 operative and 8 late), although the cause of death was unknown in 12 patients. Functional class and urgent surgical intervention were the only 2 independent predictors of late death; aortic dissection was not. ${ }^{13}$ Complications of aortic dissections claimed the lives of 4 of 6 patients who died in our series, but we could not identify any predictor of mortality, probably because of the sample size. Reoperation for AI after aortic valve-sparing operations has been uncommon in our experience, but the follow-up is still limited considering the age of our patients.

\section{LIMITATIONS}

This is a retrospective review of a prospectively followed cohort of patients operated on by 1 surgeon at a single institution, and therefore the results might not be generalizable. It is a descriptive study, and the only comparison made was with the long-term survival of the general population matched for age and sex. The number of patients who had remodeling of the aortic root was small, and the duration of follow-up after remodeling was longer than after reimplantation, thus precluding the determination of superiority of one procedure over the other.

\section{CONCLUSIONS}

Aortic valve-sparing operations provide excellent longterm valve function and low rates of valve-related complications in patients with Marfan syndrome. Reimplantation of the aortic valve is likely more durable than remodeling of the aortic root in these patients. Complications of aortic dissections remain problematic in patients with Marfan syndrome after aortic valve-sparing operations and were the most common cause of postoperative death in our series.

\section{References}

1. Murdoch JL, Walker BA, Halpern BL. Life expectancy and causes of death in the Marfan syndrome. N Engl J Med. 1972;286:804-8.

2. Silverman DI, Burton KJ, Gray J. Life expectancy in the Marfan syndrome. Am J Cardiol. 1995;75:157-60.

3. Gott VL, Greene PS, Alejo DE, Cameron DE, Naftel DC, Miller DC, et al. Replacement of the aortic root in patients with Marfan's syndrome. N Engl J Med. 1999;340:1307-13.

4. David TE, Feindel CM. An aortic valve-sparing operation for patients with aortic incompetence and aneurysm of the ascending aorta. J Thorac Cardiovasc Surg. 1992;103:617-21.

5. Birks EJ, Webb C, Child A, Radley-Smith R, Yacoub MH. Early and long-term results of a valve-sparing operation for Marfan syndrome. Circulation. 1999; 100(suppl II):II29-35. 
6. Patel ND, Weiss ES, Alejo DE, Nwakanma LU, Williams JA, Dietz HC, et al. Aortic root operations for Marfan syndrome: a comparison of the Bentall and valve-sparing procedures. Ann Thorac Surg. 2008;85:2003-10.

7. Settepani F, Szeto WY, Pacini D, De Paulis R, Chiariello L, Di Bartolomeo R, et al. Reimplantation valve-sparing aortic root replacement in Marfan syndrome using the Valsalva conduit: an intercontinental multicenter study. Ann Thorac Surg. 2007;83(suppl):S769-73

8. DePaepe AM, Devereux RB, Dietz HC, Hennekam RCM, Pyeritz RE. Revised diagnostic criteria for the Marfan syndrome. Am J Med Genet. 1996;62:417-26.

9. de Oliveira NC, David TE, Ivanov J, Armstrong S, Eriksson MJ, Rakowski H, et al. Results of surgery for aortic root aneurysm in patients with Marfan syndrome. J Thorac Cardiovasc Surg. 2003;25:789-96.

10. Perry GJ, Helmcke F, Nanda NC, Byar C, Soto B. Evaluation of aortic insufficiency by Doppler cooler flow mapping. J Am Coll Cardiol. 1987;9:952-9.

11. McDermott CD, Sermer M, Siu SC, David TE, Colman JM. Aortic dissection complicating pregnancy following prophylactic aortic root replacement in a woman with Marfan syndrome. Int J Cardiol. 2007;120:427-30.

12. Fleischer KJ, Nousari HC, Anhalt GJ, Stone CD, Laschinger JC. Immunohistochemical abnormalities of fibrillin in cardiovascular tissues in Marfan's syndrome. Ann Thorac Surg. 1997;63:1012-7.

13. Gott VL, Cameron DE, Alejo DE, Greene PS, Shake JG, Caparrelli DJ, et al. Aortic root replacement in 271 Marfan patients. A 24-year experience. Ann Thorac Surg. 2002;73:438-43.

14. David TE, Ivanov J, Armstrong S, Christie D, Rakowski H. A comparison of outcomes of mitral valve repair for degenerative disease with posterior, anterior, and bileaflet prolapse. J Thorac Cardiovasc Surg. 2005;130:1242-9.

15. David TE, Feindel CM, Webb GD, Colman JM, Armstrong S, Maganti M. Longterm results of aortic valve-sparing operations for aortic root aneurysm. J Thorac Cardiovasc Surg. 2006; 132:347-54.

16. Leyh RG, Schmidtke C, Sievers HH, Yacoub MH. Opening and closing characteristics of the aortic valve after different types of valve-preserving surgery. Circulation. 1999;100:2153-60.

17. Erasmi AW, Sievers HH, Bechtel JF, Hanke T, Stierle U, Misfeld M. Remodeling or reimplantation for valve-sparing aortic root surgery? Ann Thorac Surg. 2007; 83(suppl):S752-6.

18. Bethea BT, Fitton TP, Alejo DE, Barreiro CJ, Cattaneo SM, Dietz HC, et al. Results of aortic valve-sparing operations: experience with remodeling and reimplantation procedures in 65 patients. Ann Thorac Surg. 2004;78:767-72.

19. Leyh RG, Fischer S, Kallenbach K, Kofidis T, Pethig K, Harringer W, et al. High failure rate after valve-sparing aortic root replacement using the "remodeling technique" in acute type A aortic dissection. Circulation. 2002;106(suppl 1): I229-33.

20. Grande-Allen KJ, Cochran RP, Reinhall PG, Kunzelman KS. Re-creation of sinuses is important for sparing the aortic valve: a finite element study. Thorac Cardiovasc Surg. 2000;119:753-63.

21. Susumu K, Nobuyuki U, Seiryo S, Toshiaki H. The sinus of Valsalva relieves abnormal stress on aortic valve leaflets by facilitating smooth closure. $J$ Thorac Cardiovasc Surg. 2008;136:1528-35.

22. De Paulis R, De Matteis GM, Nardi P, Scaffa R, Colella DF, Bassano C, et al. One-year appraisal of a new aortic root conduit with sinuses of Valsalva. J Thorac Cardiovasc Surg. 2002;123:33-9.

23. Karck M, Kallenbach K, Hagl C, Rhein C, Leyh R, Haverich A. Aortic root surgery in Marfan syndrome: comparison of aortic valve-sparing reimplantation versus composite grafting. J Thorac Cardiovasc Surg. 2004;127:391-8.

\section{Discussion}

Dr Lars G. Svensson (Cleveland, Ohio). Dr David, congratulations on your excellent results in developing these operations, and thank you again for personally teaching me the reimplantation operation.

We have had similar results with 234 patients, of whom 78 had Marfan syndrome, 9 had Loeys-Dietz syndrome, and 5 had Ehlers-Danlos syndrome, and no deaths have occurred using our modification of the David reimplantation operation. Like you, we have also become more aggressive in repairing leaflets, with $35 \%$ being repaired in the last year. Indeed, in our own analysis all our patients have had a freedom from reoperation, like yours, of $96 \%$ at 9 years, with no failures in the Marfan reimplantation reoperations. However, like you, we have reported in the Annals a higher failure rate for the remodeling operation, which leads to my first question. Do you not think we now have enough information, including your greater experience, to say that the remodeling operation should be abandoned and that the David reimplantation operation is the standard of care for connective tissue disorders, when feasible?

My second question relates to the reimplantation operation and the fact that it requires meticulous technique and judgment to achieve a valve without regurgitation and no complications. A number of centers have reported difficulties, including postoperative ventricular septal defects and perforations of the anterior leaflet of the mitral valve or the membranous septum. In patients with connective tissue disorders requiring root annular reductions, we usually have used left ventricular outflow tract pledgets. Even my good friend from Stanford tells me he uses pledgets now in the septum in patients with Marfan syndrome, despite his abhorring pledgets. Could you comment on any recent modifications you have made for maybe version 6 of your operation and the use of pledgets for root reductions in patients with particularly fragile tissues?

Finally, we have no restrictions on size or degree of regurgitation for the David reimplantation operation as long as the leaflets do not have major perforations and can be repaired. In earlier articles you did restrict the use of the procedure, and you did not comment in your article on this. I was wondering whether with your greater experience you have changed your patient selection. Do you consider all patients now for the operation?

Dr David. Thank you, Dr Svensson, for the comments. I have not used the remodeling procedure in patients with Marfan syndrome since 1998. Once we discovered that some of them were dilating, we abandoned the procedure. Having said that, I think the remodeling procedure is an easy operation. It can be done in just over 1 hour, as opposed to reimplantation, which takes almost twice as long and requires much more detail at multiple levels of the outflow tract and aortic root. Therefore I do remodeling in older patients who have aortic root aneurysm and a normal nondilated aortic annulus but no longer in patients with Marfan syndrome or even so-called form fruste Marfan syndrome.

Reimplantation is a complicated operation, and in patients with fragile tissues, such as paper-thin outflow tracts, one has to be careful with the suture line along the fibrous tissue of the ventricular outflow tract to avoid holes in the mitral valve and in a membranous septum. We have not changed the technique much during the past 20 years as far as the suture line in the outflow tract. Every time we put a needle through a thin, delicate membranous septum or intervalvular fibrous body, we do use pledgets. We do not use pledgets in the muscular portion of the left ventricular outflow tract. Another important technical aspect is not to use large needles or very large sutures for that annuloplasty. The Dacron graft works as an annuloplasty. Therefore as long as the graft is secured below the nadir of the cusps, it should prevent dilatation. I usually use 4-0 polyester sutures with a very fine needle for the suture beneath the aortic annulus and try to use pledgets if the tissue is not thick enough.

Having said that, we have had 1 case of mild moderate mitral regurgitation and 1 small ventricular septal defect. It was a millimeter 
hole in both cases. We know it is there; it bothered the cardiologist and the sonographer more than the patient, but we have had this complication.

Finally, as far as expanding the indications and including patients with bad cusps, I do not believe we are there yet. I was very conservative in my first decade of experience. If I encountered any gross abnormality in the cusps, I would do a Bentall procedure. Over the past 12 or so, we became more aggressive, and if the patient does not want to have a mechanical valve-if he or she prefers a tissue valve-then you go through the extra effort to repair the aortic cusps. I have not gone to the extreme to put a patch yet in the aortic valve because our previous experience with cusp aug- mentation with pericardium was not very good. However, reinforcing the free margin with fine Gore-Tex sutures has proved to be durable and expands the rate of valve sparing in patients with aortic root aneurysms. We just reviewed 64 patients who had this technique of cusp repair, and we had no failure during the first decade of follow-up. We use Gore-Tex sutures to reinforce the free margins of cusps with large stress fenestration in the commissural areas. Hopefully this publication will appear in the Journal soon.

Dr Svensson. Thank you again for developing a great operation for us.

Dr David. Thank you for your comments. 